\title{
Relação entre zingibereno, tricomas foliares e repelência de tomateiros a Tetranychus evansi
}

\author{
Luciano Donizete Gonçalves ${ }^{(1)}$, Wilson Roberto Maluf(1), Maria das Graças Cardoso(2), \\ Juliano Tadeu Vilela de Resende ${ }^{(3)}$, Evaristo Mauro de Castro(4), Nicolau Macedo Santos ${ }^{(4)}$, \\ Ildon Rodrigues do Nascimento ${ }^{(4)}$ e Marcos Ventura Faria( ${ }^{(3)}$
}

\begin{abstract}
(1)Universidade Federal de Lavras (Ufla), Dep. de Agricultura, Campus Universitário, Caixa Postal 37, CEP 37200-000 Lavras, MG. E-mail: ludonizete@yahoo.com.br, wrmaluf@ufla.br (2)Ufla, Dep. de Química. E-mail: mcardoso@ufla.br (3)Universidade Estadual do Centro-Oeste, Dep. de Agronomia, Campus Universitário, Guarapuava, PR. E-mail: jvresende@unicento.br, mfaria@unicentro.br (4)Ufla, Dep. de Biologia. E-mail: emcastro@ufla.br, nicolauagronomia@yahoo.com.br, nascimento_ildon@yahoo.com.br
\end{abstract}

\begin{abstract}
Resumo - O objetivo deste trabalho foi quantificar os teores de zingibereno em populações segregantes $\left(\mathrm{F}_{2}\right)$ do segundo retrocruzamento para Lycopersicon esculentum a partir da espécie selvagem L. hirsutum var. hirsutum, e verificar a relação entre estes teores e a densidade de tricomas glandulares e a repelência a Tetranychus evansi. Na quantificação do zingibereno, utilizou-se um método espectrofotométrico; os tricomas foram contados a partir de cortes paradérmicos e a resistência a ácaros foi avaliada por um bioteste de repelência. A seleção indireta quanto ao teor de zingibereno promoveu aumentos correlacionados no número de tricomas glandulares e na repelência ao ácaro, e o zingibereno nos tricomas glandulares participou efetivamente na resistência aos ácaros. A densidade de tricomas glandulares influencia de maneira determinante os teores de zingibereno, sendo que o tricoma tipo VI destacou-se por apresentar alta correlação com este aleloquímico. Os teores de zingibereno e a sua relação com tricomas glandulares e com a resistência a artrópodos-pragas se mantiveram ao longo dos retrocruzamentos, evidenciando a possibilidade de obtenção de plantas resistentes via seleção indireta para alto teor de zingibereno nos folíolos.
\end{abstract}

Termos para indexação: Lycopersicon hirsutum, Lycopersicon esculentum, sesquiterpeno, ácaros.

\section{Relationship between zingiberene, foliar trichomes and repellence of tomato plant to Tetranychus evansi}

\begin{abstract}
The objective of this work was to quantify zingiberene contents in a segregating population $\left(\mathrm{F}_{2}\right)$ of the second backcross generation to Lycopersicon esculentum after the initial cross with the wild species L. hirsutum var. hirsutum, and to analyse the relationship between zingiberene and both glandular trichome density on tomato leaves and levels of repellence to spider mites Tetranychus evansi. A spectrophotometric assay was used to quantify zingiberene in leaf disks. Trichome counting was made in paradermic preparations of leaf and mite repellence was accessed by a quick thumbtack assay. Indirect selection for high zingiberene contents increased both glandular trichome density and the level of mite repellence. Zingiberene in glandular trichomes therefore mediates mite repellence in the tomato population. Glandular trichome densities, especially that of type VI trichomes, were highly and positively correlated with zingiberene contents. High zingiberene levels and their relationship with both glandular trichome densities and resistance (repellence) to spider mites remained significant after two backcross generations, indicating an indirect selection for high zingiberene as an effective way of selecting mite resistant tomato genotypes.
\end{abstract}

Index terms: Lycopersicon hirsutum, Lycopersicon esculentum, sesquiterpene, spider mites.

\section{Introdução}

O controle de artrópodos-pragas no tomateiro tem sido realizado basicamente por meio de controle químico, associado a outras práticas como o controle biológico, que apesar de ser menos expressivo, tem se mostrado eficiente no controle de algumas pragas (Barbosa \& França, 1980;
Tamai, 1997). Considerando o controle químico, énecessário grande número de aplicações de defensivos para que se garanta a produtividade. Este aspecto é preocupante, principalmente por elevar substancialmente o custo de produção, e também pelos riscos que acarreta à saúde do trabalhador rural, do consumidor e também ao meio ambiente (Vendramin, 1990). 
A dificuldade de controle de artrópodos-pragas na agricultura, aliada aos riscos oferecidos pelo controle químico - método mais empregado e até então o mais eficiente -, tem estimulado a pesquisa de novos métodos (Carvalho \& Maluf, 2000). Entre as formas de controle, a utilização de variedades resistentes é considerada como método ideal dentro de um manejo integrado de pragas, pois reduz a população da praga a quantidades inferiores às que ocasionam dano econômico, sem causar nenhum distúrbio ou poluição ao ecossistema e, ainda, sem provocar qualquer ônus adicional ao agricultor (Lara, 1979; Gallo et al., 2002).

No caso do tomate, a utilização de cultivares resistentes a artrópodos-pragas proporcionaria resultados promissores para o manejo. Alguns trabalhos têm sido desenvolvidos a partir de cruzamentos com espécies selvagens de Lycopersicon spp., que apresentam resistência a uma vasta gama de pragas. Esta resistência é conferida pela presença de substâncias químicas (aleloquímicos) excretadas por tricomas glandulares presentes nos folíolos destas espécies (Farrar Junior \& Kennedy, 1987; Carter et al., 1989; Barbosa \& Maluf, 1996; Aragão, 1998; Freitas et al., 2002).

Entre as substâncias estudadas encontra-se o zingibereno, um sesquiterpeno presente em folíolos de Lycopersicon hirsutum var. hirsutum. Sua presença foi detectada nos acessos de L. hirsutum var. hirsutum PI-126445 (Carter \& Snyder, 1985) e PI-127826 (Weston et al., 1989; Freitas et al., 2000a; Maluf et al., 2001). Segundo Carter et al. (1989), o zingibereno ocorre exclusivamente no ápice de tricomas glandulares do tipo VI, o que foi confirmado por Gianfagna et al. (1992); porém, Maluf et al. (2001) e Freitas et al. (2002) associaram a presença desse aleloquímico também ao tricoma glandular do tipo IV. Freitas et al. (2000b) estabeleceram uma metodologia espectrofotométrica de seleção de plantas com elevados teores de zingibereno, rápida, de baixo custo e não destrutiva, para a quantificação de zingibereno em populações segregantes, o que favorece programas de melhoramento genético.

Acessos da espécie Lycopersicon hirsutum var. hirsutum foram submetidos a estudos de resistência e apresentaram bons níveis de resistência ao ácaro-rajado Tetranychus urticae (Weston et al., 1989; Maluf et al., 2001), ao besouro da batata do Colorado Leptinotarsa decemlineata (Carter et al., 1989) e à mosca-branca Bemisia spp. (Freitas et al., 2002). Os resultados alcançados por Maluf et al. (2001) sugerem que a seleção para alto teor de zingibereno levaria a uma resposta correlata de maior resistência aos ácaros, causada por efeitos pleiotrópicos. Estes resultados indicam a possibilidade de obtenção de cultivares resistentes a grande número de artrópodos-pragas por meio do melhoramento genético do tomateiro a partir de genes presentes em L. hirsutum var. hirsutum.

O objetivo deste trabalho foi quantificar os teores de zingibereno em populações segregantes $\left(F_{2}\right)$ do segundo retrocruzamento para L. esculentum a partir da espécie selvagem $L$. hirsutum var. hirsutum e verificar a relação existente entre esses teores, a densidade de tricomas glandulares e a repelência a Tetranychus evansi.

\section{Material e Métodos}

Na quantificação de zingibereno, um experimento foi instalado em esquema de blocos casualizados, na empresa HortiAgro Sementes Ltda., localizada na Fazenda Palmital, no Município de Ijaci, MG. Utilizaram-se 80 plantas de L. esculentum TOM-556 e 80 plantas de L. hirsutum var. hirsutum PI-127826, 80 plantas da geração $\mathrm{F}_{1}$ do cruzamento interespecífico $\mathrm{F}_{1}$ (TOM-556 x PI-127826), 80 plantas de L. esculentum TOM-584 - utilizado como testemunha com baixo teor de zingibereno - e 400 plantas da população segregante BPX-368D. A população BPX-368D foi obtida do segundo retrocruzamento para L. esculentum a partir do acesso selvagem $L$. hirsutum var. hirsutum PI-127826.

A análise do teor de zingibereno foi realizada por meio de uma metodologia espectrofotométrica proposta por Freitas et al. (2000a). Essa metodologia consiste na retirada de seis discos foliares de folíolos jovens expandidos do terço superior das plantas, perfazendo um total de $4,21 \mathrm{~cm}^{2}$ de área foliar, os quais foram acondicionados em tubos de ensaio devidamente identificados. Posteriormente adicionaram-se $2 \mathrm{~mL}$ de hexano em cada tubo, agitando-os em seguida em aparelho vórtex por 40 segundos, para promover a extração do zingibereno. Depois da agitação, retiraram-se os discos foliares e os extratos foram submetidos à leitura de absorbância em aparelho espectrofotômetro em comprimento de onda de $270 \mathrm{~nm}$.

Com base nessa leitura, selecionaram-se plantas com teores extremos de zingibereno, as quais foram clonadas via estaquia dos brotos axilares e esses clones foram submetidos à identificação e quantificação de tricomas foliares. Os genótipos avaliados, depois da clonagem por estaquia, foram: genótipos utilizados como testemunhas 
[TOM-556 clone\#207, TOM-556 clone\#369, PI-127826 clone\#25, PI-127826 clone\#272, TOM-584 clone\#651, TOM-584 clone\#279, F 1 (TOM-556 x PI-127826) clone\#274 e $F_{1}$ (TOM-556 x PI-127826) clone\#267], genótipos da população segregante selecionados para alto teor de zingibereno (BPX-368D clone\#547, BPX-368D clone\#679, BPX-368D clone\#215, BPX-368D clone\#658, BPX-368D clone\#236, BPX-368D clone\#586 e BPX-368D clone\#361) e genótipos da população segregante selecionados para baixo teor de zingibereno (BPX-368D clone\#649, BPX-368D clone\#69, BPX-368D clone\#676, BPX-368D clone\#441, BPX-368D clone\#78 e BPX-368D clone\#165).

Três plantas de cada clone foram mantidas em casa de vegetação, em delineamento inteiramente casualizado. Depois de 50 dias do transplantio para os vasos, foram retirados quatro folíolos jovens e expandidos do terço médio de cada planta. Na avaliação do número de tricomas (número médio por $\mathrm{cm}^{2}$ ), realizaram-se três cortes paradérmicos na epiderme das faces abaxial e três na adaxial, em cada um dos quatro folíolos retirados, montando-se lâminas semipermanentes que foram submetidas à contagem de tricomas com o auxílio de câmara clara, em microscópio com objetiva de 20X, segundo técnica adaptada de Labouriau et al. (1961). A classificação dos tricomas foi feita com base na presença ou ausência de glândula na extremidade apical do tricoma e também no comprimento do tricoma e tipo de glândula (Luckwill, 1943), seguindo as características evidenciadas por Aragão (1998).

Para avaliação da relação entre teor de zingibereno e tricomas foliares com a repelência a ácaros, foi utilizado o ácaro-vermelho Tetranychus evansi. Foram submetidos a este ensaio seis clones selecionados para alto teor de zingibereno (BPX-368D clone\#679, BPX-368D clone\#215 e BPX-368D clone\#658, BPX-368D clone\#236, BPX-368D clone\#361, BPX-368D clone\#547) e três clones selecionados para baixo teor deste aleloquímico (BPX-368D clone\#649, BPX-368D clone\#676 e BPX-368D clone\#441). Além dessa população de plantas segregantes, foram avaliadas a geração $\mathrm{F}_{1}$ (TOM-556 x PI-127826) e as testemunhas para baixo teor ( $L$. esculentum, linhagens TOM-556e TOM-584) e alto teor de zingibereno (L. hirsutum var. hirsutum PI-127826). A resistência ao ácaro foi quantificada segundo teste de repelência proposto por Weston \& Snyder (1990), medindo-se as distâncias percorridas pelos ácaros sobre os folíolos dos genótipos nos tempos de 20, 40 e 60 minutos, contados a partir da colocação de dez ácaros fêmeas em uma tachinha metálica fixada no centro de cada folíolo.

Os dados de tricomas foram analisados de maneira individualizada para tricomas glandulares tipo IV, tipo VI, total de tricomas glandulares (I + IV + VI + VII) e tricomas não-glandulares, nas superfícies abaxial e adaxial dos folíolos. Analisaram-se as correlações entre teor de zingibereno e tricomas foliares e também distância percorrida pelo ácaro. Para o bioteste com o ácaro-vermelho, foram realizados contrastes de interesse entre os genótipos avaliados quanto à distância percorrida pelo ácaro, além de se avaliar a correlação entre o teor de zingibereno e essa distância.

\section{Resultados e Discussão}

A análise química dos genótipos confirmou a eficiência da metodologia de seleção de plantas com teores contrastantes de zingibereno nos folíolos. Assim, foram selecionados genótipos com níveis extremos de zingibereno nos folíolos, compreendendo 14 plantas da população segregante BPX-368D, duas plantas de L. hirsutum var. hirsutum, duas plantas de L. esculentum TOM-556 e duas de TOM-584, e também duas plantas da geração $\mathrm{F}_{1}$ (TOM-556 x PI-127826). Entre as plantas selecionadas, três apresentaram níveis bastante elevados de zingibereno, sendo duas plantas do acesso selvagem L. hirsutum var. hirsutum (PI-127826 clone\#025 e PI-127826 clone\#272), cujos valores de absorbância das amostras foram de 0,7951 e 0,8355 , respectivamente, e uma planta da população de retrocruzamento (BPX-368D clone\#679), com leitura média de absorbância de 0,6634 (Tabela 1). As plantas dos acessos de L. esculentum TOM-556 clone\#207, TOM-556 clone\#369, TOM-584 clone\#279 e TOM-584 clone\#651 (com valores de absorbância de 0,0655, $0,1368,0,2256$ e 0,1919 , respectivamente) situaram-se no grupo dos genótipos que apresentaram os mais baixos teores de zingibereno nos folíolos, cujas médias foram de 0,2069 e 0,2054, para TOM-556 e TOM-584, respectivamente. Os resultados confirmaram a diferença pronunciada entre a concentração desse aleloquímico nos genótipos comercial e selvagem, visto que a absorbância das amostras do acesso selvagem foi superior à das linhagens comerciais. (Tabela 1).

Entre as plantas selecionadas da população BPX-368D, o genótipo BPX-368-D clone\#679 apresentou teor de zingibereno bastante elevado, com 
leitura média de absorbância de 0,6634 (Tabela 1), próxima das de PI-127826. A análise química das 400 plantas da população BPX-368D mostrou um maior número de plantas com baixos teores de zingibereno, o que pode ser reflexo da dominância do alelo, ou dos alelos, que condiciona esse fenótipo, e indica preponderância da ação gênica de dominância parcial no sentido de menores teores de zingibereno, conforme Freitas (1999).

A análise de variância em tricomas glandulares tipo IV, tanto da face abaxial quanto da adaxial, mostrou diferenças significativas entre os genótipos avaliados. Porém, essa diferença foi mais pronunciada no parental selvagem PI-127826 (Tabela 1). Os genótipos utilizados como testemunhas para baixo teor de zingibereno, TOM-556 e TOM-584, não apresentaram este tipo de tricoma, o que ocorreu também naqueles genótipos da população segregante selecionados para baixo teor do aleloquímico.

Quanto ao número de tricomas glandulares do tipo VI nos folíolos, entre os genótipos avaliados, o PI-127826 apresentou maior número médio de tricomas por $\mathrm{cm}^{2}$ de área foliar (897,3 e 993,3, nas faces abaxial e adaxial, respectivamente) (Tabela 1) e alguns genótipos selecionados quanto ao alto teor de zingibereno apresentaram maior quantidade de tricomas tipo VI que os demais. Esses resultados se repetiram na análise do número de tricomas glandulares totais (tipo I + IV + VI + VII), em ambas as faces, confirmando que o parental selvagem PI-127826 apresenta maior número de tricomas glandulares em relação às linhagens comerciais avaliadas. Essa proporção foi parcialmente mantida nos genótipos pré-selecionados quanto ao alto teor do zingibereno.

A correlação entre o teor de zingibereno e a quantidade de tricomas glandulares tipo IV (Tabela 1) não foi significativa nas faces abaxial e adaxial $(r=0,15$ e $r=0,22$, respectivamente). A correlação foi significativa apenas para os tricomas glandulares tipo VI na face abaxial $(r=0,75)$, demonstrando que o zingibereno está positivamente correlacionado com esse tipo de tricoma presente na face abaxial foliolar. Assim, fica também evidente que a maior parte do zingibereno em folíolos de tomateiro é liberada pelas glândulas contidas principalmente na extremidade do tricoma do tipo VI.

Quando se analisou a correlação entre teor de zingibereno e o total de tricomas glandulares (tipo I + IV + VI + VII), verificou-se efeito significativo apenas na face abaxial foliolar, e a correlação encontrada foi ligeiramente superior $(r=0,81)$ à encontrada para tipo VI apenas (Tabela 1), indicando que o zingibereno pode estar contido também, ainda que em pequena concentração, nos demais tricomas glandulares.

Tabela 1. Teores de zingibereno e número médio de tricomas glandulares e não glandulares nas superfícies abaxial (ab) e adaxial (ad) em genótipos de tomateiro ${ }^{(1)}$.

\begin{tabular}{|c|c|c|c|c|c|c|c|c|c|}
\hline \multirow[t]{3}{*}{ Genótipo } & \multirow{3}{*}{$\begin{array}{l}\text { Zingibereno } \\
\text { (absorbância } \\
\text { a } 270 \mathrm{~nm} \text { ) }\end{array}$} & \multicolumn{8}{|c|}{ Tricomas $\mathrm{cm}^{-2}$} \\
\hline & & \multicolumn{6}{|c|}{ Glandulares } & \multicolumn{2}{|c|}{ Não-glandulares II+III+V } \\
\hline & & IV - ab & IV - ad & $\mathrm{VI}-\mathrm{ab}$ & VI - ad & $\begin{array}{c}\text { Total - ab } \\
(\mathrm{I}+\mathrm{IV}+\mathrm{VI}+\mathrm{VII})\end{array}$ & $\begin{array}{c}\text { Total - ad } \\
(\mathrm{I}+\mathrm{IV}+\mathrm{VI}+\mathrm{VII})\end{array}$ & $\mathrm{ab}$ & $\mathrm{ad}$ \\
\hline TOM-556 & 0,2069 & $0,0 \mathrm{~b}$ & $0,0 \mathrm{~b}$ & $14,0 \mathrm{~b}$ & $14,0 \mathrm{c}$ & $36,0 \mathrm{~b}$ & $28,0 \mathrm{~b}$ & $14.890,0 \mathrm{a}$ & $12.436,0 \mathrm{ab}$ \\
\hline TOM-584 & 0,2054 & $0,0 \mathrm{~b}$ & $0,0 \mathrm{~b}$ & $6,4 \mathrm{~b}$ & $10,4 \mathrm{c}$ & $10,8 b$ & $57,6 \mathrm{~b}$ & $13.536,0 \mathrm{a}$ & $12.168,0 \mathrm{ab}$ \\
\hline PI-127826 & 0,8542 & $8.824,0 \mathrm{a}$ & $8.226,7 \mathrm{a}$ & $897,3 \mathrm{a}$ & $993,3 \mathrm{a}$ & $9.873,3 \mathrm{a}$ & $9.401,3 \mathrm{a}$ & $32,0 \mathrm{~b}$ & $89,0 \mathrm{c}$ \\
\hline $\mathrm{F}_{1}(\mathrm{TOM} 556$ x PI-127826) & 0,2069 & $89,6 \mathrm{~b}$ & $41,6 b$ & $179,2 b$ & $411,2 b c$ & $318,4 \mathrm{~b}$ & $518,4 \mathrm{~b}$ & $13.107,0 \mathrm{a}$ & $8.222,0 \mathrm{~b}$ \\
\hline BPX-368D clone $\# 679$ & 0,6634 & $5,3 \mathrm{~b}$ & $12,0 \mathrm{~b}$ & $144,0 \mathrm{~b}$ & $296,0 \mathrm{bc}$ & $181,3 b$ & $414,7 b$ & $14.973,0 \mathrm{a}$ & $13.608,0 \mathrm{a}$ \\
\hline BPX-368D clone\#215 & 0,3867 & $26,7 b$ & $52,0 \mathrm{~b}$ & $82,7 \mathrm{~b}$ & $304,0 \mathrm{bc}$ & $148,0 \mathrm{~b}$ & $502,7 \mathrm{~b}$ & $13.333,0 \mathrm{a}$ & $12.384,0 \mathrm{ab}$ \\
\hline BPX-368D clone\#658 & 0,3691 & $0,0 \mathrm{~b}$ & $0,0 \mathrm{~b}$ & $64,0 \mathrm{~b}$ & $325,3 \mathrm{bc}$ & $133,3 b$ & $488,0 \mathrm{~b}$ & $15.352,0 \mathrm{a}$ & $14.312,0 \mathrm{a}$ \\
\hline BPX-368D clone\#236 & 0,3577 & $0,0 \mathrm{~b}$ & $0,0 \mathrm{~b}$ & $88,0 \mathrm{~b}$ & $157,3 \mathrm{c}$ & $146,7 b$ & $253,3 b$ & $13.227,0 \mathrm{a}$ & $12.709,0 \mathrm{ab}$ \\
\hline BPX-368D clone\#361 & 0,3567 & $2,7 \mathrm{~b}$ & $0,0 \mathrm{~b}$ & $98,7 \mathrm{~b}$ & $117,3 \mathrm{c}$ & $146,7 b$ & $154,7 b$ & $16.840,0 \mathrm{a}$ & $14.320,0 \mathrm{a}$ \\
\hline BPX-368D clone\#586 & 0,2655 & $0,0 \mathrm{~b}$ & $0,0 \mathrm{~b}$ & $69,3 b$ & $608,0 \mathrm{~b}$ & $77,3 b$ & $720,0 \mathrm{~b}$ & $12.408,0 \mathrm{a}$ & $11.976,0 \mathrm{ab}$ \\
\hline BPX-368D clone\#547 & 0,2307 & $2,0 \mathrm{~b}$ & $6,0 \mathrm{~b}$ & $32,0 \mathrm{~b}$ & $93,3 \mathrm{c}$ & $63,3 b$ & $251,3 b$ & $16.179,0 \mathrm{a}$ & $13.429,0 \mathrm{ab}$ \\
\hline BPX-368D clone $\# 649$ & 0,1867 & $2,7 \mathrm{~b}$ & $2,7 b$ & $29,3 b$ & $66,7 \mathrm{c}$ & $38,0 \mathrm{~b}$ & $104,0 \mathrm{~b}$ & $14.523,0 \mathrm{a}$ & $12.560,0 \mathrm{ab}$ \\
\hline BPX-368D clone \#676 & 0,1696 & $0,0 \mathrm{~b}$ & $0,0 \mathrm{~b}$ & $12,0 \mathrm{~b}$ & $70,7 \mathrm{c}$ & $22,7 b$ & $124,0 \mathrm{~b}$ & $13.651,0 \mathrm{a}$ & $12.763,0 \mathrm{ab}$ \\
\hline BPX-368D clone\#69 & 0,1686 & $0,0 \mathrm{~b}$ & $0,0 \mathrm{~b}$ & $46,0 \mathrm{~b}$ & $60,8 \mathrm{c}$ & $70,0 \mathrm{~b}$ & $124,0 \mathrm{~b}$ & $14.448,0 \mathrm{a}$ & $12.204,0 \mathrm{ab}$ \\
\hline BPX-368D clone\#78 & 0,1225 & $0,0 \mathrm{~b}$ & $2,7 \mathrm{~b}$ & $18,0 \mathrm{~b}$ & $70,7 \mathrm{c}$ & $31,3 b$ & $129,3 b$ & $17.485,0 \mathrm{a}$ & $11.787,0 \mathrm{ab}$ \\
\hline BPX-368D clone\#165 & 0,1205 & $0,0 \mathrm{~b}$ & $0,0 \mathrm{~b}$ & $26,7 b$ & $26,7 \mathrm{c}$ & $40,0 \mathrm{~b}$ & $58,7 \mathrm{~b}$ & $15.955,0 \mathrm{a}$ & $14.011,0 \mathrm{a}$ \\
\hline BPX -368D clone $\# 441$ & 0,0893 & $6,7 \mathrm{~b}$ & $1,3 \mathrm{~b}$ & $12,7 \mathrm{~b}$ & $410,3 b c$ & $30,0 \mathrm{~b}$ & $467,0 \mathrm{~b}$ & $15.227,0 \mathrm{a}$ & $12.397,0 \mathrm{ab}$ \\
\hline Coef. de corr. com zingibere & & $0,15^{\mathrm{ns}}$ & $0,22^{\mathrm{ns}}$ & $0,75^{* *}$ & $0,19^{\mathrm{ns}}$ & $0,81^{* *}$ & $0,27^{\mathrm{ns}}$ & $0,09^{\mathrm{ns}}$ & $0,17^{\mathrm{ns}}$ \\
\hline
\end{tabular}

(1)Médias seguidas da mesma letra, nas colunas, não diferem entre si pelo teste de Tukey a $5 \%$ de probabilidade. ${ }^{* *}$ Significativo a $1 \%$ de probabilidade pelo teste F. 
Os resultados obtidos neste trabalho, no entanto, indicam que o zingibereno está associado especialmente aos tricomas tipo VI e mostram a sua maior presença na superfície abaxial dos folíolos dos genótipos avaliados. Esse resultado concorda em parte com Freitas et al. (2002), que atribuíram a presença do sesquiterpeno aos tricomas glandulares, especialmente os de tipo VI e IV.

Em linhagens comerciais (TOM-584 e TOM-556), predominaram os tricomas não-glandulares em ambas as faces estudadas. Contrariamente, nos folíolos do acesso selvagem L. hirsutum var. hirsutum, predominaram os glandulares (Tabela 1). Quanto aos clones da população segregante BPX-368D, verificaram-se pequenas variações nos níveis de tricomas. Porém, genótipos com alto teor de zingibereno apresentaram também maior quantidade de tricomas glandulares, particularmente do tipo VI, o que evidencia a eficiência do método de análise colorimétrica do zingibereno na seleção de plantas com alto teor deste aleloquímico em programas de melhoramento do tomateiro visando resistência a artrópodos-pragas. Estes resultados concordam com os publicados por Maluf et al. (2001) e Freitas et al. (2002), que utilizaram esta metodologia de análise química para seleção de plantas em populações segregantes, e também reafirmam os tipos de tricomas apresentados no acesso selvagem e nas linhagens comerciais que utilizaram.

A associação, inicialmente encontrada por Maluf et al. (2001) e Freitas et al. (2002), entre as características teor de zingibereno e densidade de tricomas glandulares, manteve-se ao longo das gerações adicionais de retrocruzamentos. Dessa forma, é possível inferir que essas características possam ser controladas por genes ligados, ou mesmo que ocorra um efeito pleiotrópico para suas expressões. No entanto, considerando que este trabalho foi realizado em uma população mais avançada (população $\mathrm{F}_{2}$ do segundo retrocruzamento) do que a daqueles autores, é mais provável a existência de pleiotropia, visto que o maior número de retrocruzamentos eleva as chances de quebra de ligações gênicas, e isto não ocorreu até a presente geração testada, pois ambas as características se expressaram correlacionadas nos genótipos avaliados.

A avaliação da população BPX-368D e das testemunhas em ensaio biológico com o ácaro-vermelho apresentou diferenças significativas (Tabela 2) quanto à repelência ao ácaro, em todos os tempos avaliados (20, 40 e 60 minutos). A distância média percorrida pelos ácaros foi significativamente inferior no acesso selvagem PI-127826 em todos os tempos de avaliação, quando comparada com as linhagens TOM-584 e TOM-556 nas três avaliações, conforme acusam as estimativas dos contrastes que comparam esses tratamentos (Tabela 2), confirmando o elevado nível de repelência ao ácaro da espécie selvagem. Na população segregante, em materiais selecionados para alto teor de zingibereno, os ácaros também apresentaram menor distância de caminhamento sobre os folíolos (Tabela 2).

A menor distância percorrida pelo ácaro foi registrada pelo acesso PI-127826, seguido pelos genótipos BPX-368D clone\#236, BPX-368D clone\#215 e BPX-368D clone\#679, sendo estes os que apresentaram maiores teores de zingibereno na análise colorimétrica. O contraste que compara os clones com altos teores de zingibereno com o parental L. hirsutum var. hirsutum PI-127826 não apresentou estimativas significativas, confirmando mais uma vez a eficiência do zingibereno em reduzir o deslocamento do ácaro, e também ratificando a eficiência na seleção de plantas resistentes ao ácaro com base na análise colorimétrica, uma vez que os genótipos selecionados apresentaram comportamento semelhante ao parental, cuja

Tabela 2. Teores de zingibereno, distâncias percorridas pelos ácaros nos tempos avaliados e contrastes de interesse de 13 genótipos de tomateiro ${ }^{(1)}$.

\begin{tabular}{|c|c|c|c|c|}
\hline \multirow[t]{2}{*}{ Genótipo } & \multirow[t]{2}{*}{$\begin{array}{l}\text { Zingibereno (absorbância } \\
\text { a } 270 \mathrm{~nm} \text { ) }\end{array}$} & \multicolumn{3}{|c|}{$\begin{array}{c}\text { Distância média percorrida por } \\
\text { ácaro (mm) }\end{array}$} \\
\hline & & $20 \mathrm{~min}$ & $40 \mathrm{~min}$ & $60 \mathrm{~min}$ \\
\hline TOM-556 & 0,2069 & $12,92 \mathrm{ab}$ & $12,25 \mathrm{ab}$ & $14,92 \mathrm{abc}$ \\
\hline TOM-584 & 0,2054 & $16,10 \mathrm{a}$ & $17,30 \mathrm{a}$ & $17,87 \mathrm{a}$ \\
\hline PI-127826 & 0,8542 & $5,60 \mathrm{~b}$ & $6,05 b$ & $5,82 \mathrm{c}$ \\
\hline $\mathrm{F}_{1}(\mathrm{TOM} 556 \times \mathrm{PI}-127826)$ & 0,2069 & $6,35 b$ & $8,72 \mathrm{ab}$ & $9,82 \mathrm{abc}$ \\
\hline BPX-368D clone\#679 & 0,6634 & $7,77 \mathrm{ab}$ & $7,15 b$ & $7,92 \mathrm{bc}$ \\
\hline BPX-368D clone\#215 & 0,3867 & $6,17 \mathrm{~b}$ & $6,77 \mathrm{~b}$ & $6,95 b c$ \\
\hline BPX-368D clone\#658 & 0,3691 & $9,52 \mathrm{ab}$ & $10,37 \mathrm{ab}$ & $11,05 \mathrm{abc}$ \\
\hline BPX-368D clone\#236 & 0,3577 & $6,35 \mathrm{~b}$ & $5,50 \mathrm{~b}$ & $7,52 \mathrm{bc}$ \\
\hline BPX-368D clone\#361 & 0,3567 & $9,42 \mathrm{ab}$ & $9,32 \mathrm{ab}$ & $10,02 \mathrm{abc}$ \\
\hline BPX-368D clone $\# 547$ & 0,2307 & $9,90 \mathrm{ab}$ & $10,42 \mathrm{ab}$ & $10,87 a b c$ \\
\hline BPX-368D clone\#649 & 0,1867 & $9,17 \mathrm{ab}$ & $10,70 \mathrm{ab}$ & $13,42 \mathrm{abc}$ \\
\hline BPX-368D clone\#676 & 0,1696 & $11,47 \mathrm{ab}$ & $12,02 \mathrm{ab}$ & $13,20 \mathrm{abc}$ \\
\hline BPX-368D clone\#441 & 0,0893 & $15,82 \mathrm{a}$ & $12,17 \mathrm{ab}$ & $15,22 \mathrm{ab}$ \\
\hline \multicolumn{2}{|l|}{ Contraste de interesse } & \multicolumn{3}{|c|}{ - } \\
\hline PI-127826 vs. TOM-556 & & $-7,32^{* *}$ & $-6,20^{*}$ & $-9,10^{* *}$ \\
\hline PI-127826 vs. TOM-584 & & $-10,50^{* *}$ & $-11,25^{* *}$ & $-12,05^{* *}$ \\
\hline PI-127826 vs. $F_{1}$ (TOM556 & I-127826) & $-0,75^{\text {ns }}$ & $-2,67^{\mathrm{ns}}$ & $-4,00^{\mathrm{ns}}$ \\
\hline $\mathrm{F}_{1}(\mathrm{TOM} 556 \times \mathrm{PI}-127826) \mathrm{v}$ & TOM-556 & $-6,57^{*}$ & $-3,52^{\text {ns }}$ & $-5,10^{\text {ns }}$ \\
\hline Clones altos vs. clones baix & & $-3,74^{* *}$ & $-3,51^{* *}$ & $-4,49^{* *}$ \\
\hline PI-127826 vs. clones altos & & $-2,25^{\mathrm{ns}}$ & $-1,77^{\mathrm{ns}}$ & $-2,87^{\mathrm{ns}}$ \\
\hline PI-127826 vs. clones baixos & & $-5,99^{* *}$ & $-5,28^{*}$ & $-7,36^{* *}$ \\
\hline TOM-556 vs. clones altos & & $+5,07^{*}$ & $+4,42^{*}$ & $+6,23^{* *}$ \\
\hline TOM-556 vs. clones baixos & & $+1,33^{\text {ns }}$ & $+0,92^{\text {ns }}$ & $+1,74^{\text {ns }}$ \\
\hline \multicolumn{5}{|l|}{ Correlações lineares (r) } \\
\hline Dist. percorridas vs. teor de & agibereno & $-0,679^{*}$ & $-0,729^{*}$ & $-0,80^{*} 2$ \\
\hline
\end{tabular}


característica de resistência já foi explicitada em outros trabalhos (Maluf et al., 2001; Freitas et al., 2002). Em contrapartida, nos três tempos avaliados, as distâncias médias percorridas pelos ácaros sobre os folíolos dos clones selecionados quanto ao alto teor de zingibereno foram significativamente inferiores àquelas percorridas sobre a linhagem TOM-556, conforme estimativas do contraste que comparam esses genótipos (Tabela 2).

As estimativas do contraste que compara a média do grupo de genótipos selecionados para baixo teor de zingibereno com o acesso PI-127826, quanto ao caminhamento dos ácaros sobre os folíolos, demonstraram que a distância média percorrida foi significativamente maior nos clones de baixo teor do que no acesso selvagem, independentemente do tempo de avaliação (Tabela 2). Como se esperava, estes clones não apresentaram diferenças em relação à linhagem TOM-556 e, portanto, não apresentaram nenhum tipo de resistência ao ácaro. O contraste que compara as distâncias médias percorridas pelos ácaros, entre as médias dos clones com altos teores e baixos teores de zingibereno nos folíolos foi significativo para todos os tempos de avaliação, confirmando assim a diferença de comportamento do ácaro sobre os diferentes genótipos com diferentes concentrações do aleloquímico. As correlações obtidas entre as distâncias percorridas pelos ácaros e o teor de zingibereno nos folíolos foram significativas e negativas aos 20, 40 e 60 minutos (Tabela 2), confirmando a associação entre alto teor do aleloquímico e a repelência aos ácaros.

A avaliação da resistência desses genótipos ao ácarovermelho mostrou que o comportamento das plantas da população BPX-368D, selecionadas para alto teor de zingibereno, foi semelhante ao acesso silvestre PI-127826 em promover repelência ao ácaro. A repelência não foi observada nas linhagens comerciais TOM-556 e TOM-584, tampouco nos clones selecionados para baixo teor. Confirma-se que o zingibereno nos tricomas glandulares dos genótipos avaliados é responsável pela repelência aos ácaros.

A seleção indireta de clones, com altos teores de zingibereno, foi eficiente na obtenção de maior repelência aos ácaros, e esses clones serão utilizados na continuidade do programa de melhoramento. A seleção de genótipos com boa resistência via avaliação direta no campo com a infestação do artrópodo-praga, ou mesmo em condições controladas, pode inviabilizar o trabalho com uma população grande de plantas, como é o caso de populações segregantes.
Este trabalho demonstra que tal procedimento pode ser viabilizado por meio de seleção indireta para altos teores de zingibereno. Demonstra ainda que o padrão de resistência de plantas de tomateiro se mantém, ao longo do avanço das gerações, visto que a avaliação foi realizada na população do segundo retrocruzamento para $L$. esculentum, em que também as quantidades de tricomas nos folíolos foram mantidas, bem como o efeito dos genótipos sobre o caminhamento dos ácaros. Freitas et al. (2002) obtiveram estimativas de herdabilidades altas para essas características, o que deve refletir-se em ganhos genéticos satisfatórios para a resistência a artrópodos-pragas, quando se realiza a seleção indireta. Uma vez que as características de resistência se mantêm ao longo dos retrocruzamentos, é possível avançar no programa de melhoramento com perspectivas de obtenção de cultivares resistentes.

\section{Conclusões}

1. O teor de zingibereno em folíolos de tomateiro está correlacionado com a presença de tricomas glandulares, principalmente do tipo VI.

2. A avaliação de tricomas glandulares apenas na face abaxial do folíolo é suficiente para a seleção de plantas com teores elevados de zingibereno.

3. O zingibereno é efetivo em conferir repelência de genótipos de tomateiro ao ácaro-vermelho Tetranychus evansi.

4. A seleção indireta de plantas com base na concentração do zingibereno é eficiente na obtenção de genótipos com elevada resistência ao ácaro-vermellho Tetranychus evansi.

5. O teor de zingibereno e a densidade de tricomas glandulares se mantêm associadas ao longo dos retrocruzamentos, bem como a resistência dos genótipos ao ácaro-vermelho.

\section{Agradecimentos}

À Capes, à Fapemig e ao CNPq, pelo apoio financeiro; à Universidade Federal de Lavras e à HortiAgro Sementes Ltda., pelo apoio financeiro e pelo espaço cedido.

\section{Referências}

ARAGÃO, C.A. Tricomas foliares associados à resistência ao ácaro rajado em linhagens de tomateiro com alto teor de 
2-tridecanona nos folíolos. 1998. 71p. Dissertação (Mestrado) Universidade Federal de Lavras, Lavras.

BARBOSA, L.V.; MALUF, W.R. Heritability of 2-tridecanonemediated arthropod resistance in an interspecific segregating generation of tomato. Revista Brasileira de Genética, v.19, p.465468, 1996.

BARBOSA, S.; FRANÇA, F.H. As pragas do tomateiro e seu controle. Informe Agropecuário, v.6, p.37-40, 1980.

CARTER, C.D.; SACALIS, J.N.; GIANFAGNA, T.J. Zingiberene and resistance to Colorado potato beetle in Lycopersicon hirsutum f. hirsutum. Journal of Agricultural and Food Chemistry, v.37, p.206-210, 1989.

CARTER, C.D.; SNYDER, J.C. Mite responses in relation to trichomes of Lycopersicon esculentum x Lycopersicon hirsutum $\mathrm{F}_{2}$ hybrids. Euphytica, v.34, p.177-185, 1985.

CARVALHO, G.A.; MALUF, R.P. Táticas de baixo impacto ambiental no manejo de insetos. Lavras: Ufla; Faepe, 2000. 33p.

FARRAR JUNIOR, R.R.; KENNEDY, G.G. 2-Undecanone, a constituent of the glandular trichomes of Lycopersicon hirsutum f. glabratum: effects on Heliothis zea and Manduca sexta growth and survival. Entomologia Experimentalis et Applicata, v.43, p.17-23, 1987.

FREITAS, J.A. Resistência genética do tomateiro Lycopersicon sp. à mosca branca Bemisia spp. mediada por zingibereno contido em tricomas glandulares. 1999. 93p. Tese (Doutorado) Universidade Federal de Lavras, Lavras.

FREITAS, J.A.; MALUF, W.R.; CARDOSO, M.G.; BENITES, F.R.G. Métodos para quantificação do zingibereno em tomateiro, visando à seleção indireta de plantas resistentes aos artrópodespraga. Acta Scientiarum, v.22, p.943-949, 2000a.

FREITAS, J.A.; MALUF, W.R.; CARDOSO, M.G.; GOMES, L.A.A.; BEARZOTTI, E. Inheritance of foliar zingiberene contents and their relationship to trichome densities and whitefly resistance in tomatoes. Euphytica, v.127, p.275-287, 2002.

FREITAS, J.A.; MALUF, W.R.; CARDOSO, M.G.; OLIVEIRA, A.C.B. Seleção de plantas de tomateiro visando à resistência à artrópodes-praga mediada por zingibereno. Acta Scientiarum, v.22, p.919-923, 2000b.
GALLO, D.; NAKANO, O.; SILVEIRA NETO, S.S.; CARVALHO, R.P.L.; BAPTISTA, G.C.; BERTI FILHO, E.; PARRA, J.R.P.; ZUCCHI, R.A.; ALVES, S.B.; VENDRAMIM, J.D.; MARCHINI, L.C.; LOPES, J.R.S.; OMOTO, C. Entomologia Agrícola. Piracicaba: Esalq, 2002. 920p.

GIANFAGNA, T.J.; CARTER, C.D.; SACALIS, J.N. Temperature and photoperiod influence trichome density and sesquiterpene content of Lycopersicon hirsutum f. hirsutum. Plant Physiology, v.100, p.1403-1405, 1992.

LABOURIAU, L.G.; OLIVEIRA, J.G.; SALGADO-LABOURIAU, M.L. Transpiração de Schizolobium parahyba (Vell.) Toledo. I. Comportamento na estação chuvosa, nas condições de Caeté, Minas Gerais, Brasil. Anais da Academia Brasileira de Ciências, v.33, p.237-257, 1961.

LARA, F.M. Princípios de resistência de plantas a insetos. Piracicaba: Livroceres, 1979. 207p.

LUCKWILL, L.C. The genus Lycopersicon: an historical, biological, and taxonomic survey of the wild and cultivated tomatoes. Aberdeen: Aberdeen University Press, 1943.

MALUF, W.R.; CAMPOS, G.A.; CARDOSO, M.G. Relationships between trichome types and spider mite (Tetranychus evansi) repellence in tomatoes with respect to foliar zingiberene contents. Euphytica, v.121, p.73-80, 2001.

TAMAI, M.A. Avaliação de fungos entomopatogênicos para o controle de Tetranychus urticae (Koch). 1997. 85p. Dissertação (Mestrado) - Escola Superior de Agricultura Luiz de Queiroz, Piracicaba.

VENDRAMIN, J.D. A resistência de plantas e o manejo de pragas. In: CROCOMO, W.B. Manejo integrado de pragas. São Paulo: Unesp, 1990. p.177-197.

WESTON, P.A.; JOHNSON, D.A.; BURTON, H.T.; SNYDER, J.C. Trichome secretion composition, trichome densities and spider mite resistance of ten accessions of Lycopersicon hirsutum. Journal of the American Society for Horticultural Science, v.114, p.492498, 1989.

WESTON, P.A.; SNYDER, J.C. Thumbtack bioassay: a quick method of measuring plant resistance to twospotted spider mites (Acari: Tetranychidae). Journal of Economic Entomology, v.83, p.500-504, 1990.

Recebido em 18 de fevereiro de 2005 e aprovado em 10 de junho de 2005 